\title{
Exposure to Selected Air Pollutants in the Grilling Process
}

Artur J Badyda ${ }^{1}$, Wioletta Rogula-Kozłowska ${ }^{2}$, Grzegorz Majewski ${ }^{3}$, Przemysław

Oberbek $^{4}$, Kamila Widziewicz ${ }^{5}$, Izabela Jureczko ${ }^{6}$, Mariusz Rogulski ${ }^{1}$

1. Faculty of Building Services, Hydro- and Environmental Engineering, Warsaw University of Technology, POLAND, 00-653 Warsaw, Nowowiejska 20, E-mail: artur.badyda@pw.edu.pl

2. The Main School of Fire Service, Faculty of Fire Safety Engineering, POLAND, 01-629 Warsaw, Słowackiego 52/54, E-mail: wrogula@sgsp.edu.pl

3. Faculty of Civil and Environmental Engineering, Warsaw University of Life Sciences, POLAND, 02-776 Warsaw, Nowoursynowska 159, E-mail: grzegorz_majewski@sggw.pl

4. Central Institute for Labour Protection - National Research Institute, POLAND, Czerniakowska 16, 00-701 Warsaw, E-mail: ober@ciop.pl

5. Institute of Environmental Engineering, Polish Academy of Sciences, POLAND, 41-819 Zabrze, Marii Skłodowskiej-Curie 34, E-mail: kamila.widziewicz@ipis.zabrze.pl

6. Power Research \& Testing Company “ENERGOPOMIAR” Ltd, POLAND, 44-100 Gliwice, Gen. J. Sowińskiego 3 St., E-mail: bell_007@o2.pl

Epidemiological evidence indicate that exposure to polycyclic aromatic hydrocarbons (PAHs) consumed with grilled meat might be hazardous for health. We used 3 different types of grills. 16 PAHs congeners were measured. PAHs exposure to charcoal briquettes incineration products might be even 10 times higher than in case of other types of barbecues.

Keywords - Barbecue, grill, lump charcoal, charcoal briquettes, propane, electric grill, inhalation exposure, particulate matter, polycyclic aromatic hydrocarbons, Monte Carlo simulation.

\section{Introduction}

Epidemiological evidence indicate that exposure to polycyclic aromatic hydrocarbons (PAHs) consumed with grilled meat might be hazardous for human health. In scientific literature however there is still lack of data concerning inhalation exposure to those compounds which are present in the barbecue exhausting gases. First investigation, made 2 years before, indicated that the inhalation cancer risk of the grill master could reach the level of 7.01-8.68 $\times 10^{-1}$, which is on the unacceptable level. The main goal of the present analysis was to confirm the results of the first investigation and assess the possible cancer risk from the exposure to PM-bound PAHs generated during barbecuing, not only in the grill master but also people staying nearby the grill, witnessing the grilling process. The comparison of the risk, which can be experienced during the grilling process depending on the type of grill and fuel used for its powering, will also be presented. Alimentary and dermal risk has also been considered, however the results of the inhalation risk assessment will only be presented.

\section{Materials and methods}

The investigation was completed with the use of 3 different types of grills: a traditional one powered by two different types of fuels: lump charcoal (LC) and charcoal briquettes (CB) as well as the grill powered by liquid propane (LP) and electric energy (E). In case of each grill and fuel the exposure for PAHs and VOCs (BTX) of a grill master and other people has been investigated. Appropriate samples has also been taken in the control area, which was located in a certain distance from the grill position. In each case 3 separate types of samples has been collected: during the combustion of fuel itself (except the electric grill) and then while grilling vegetables and meat dishes. 
The measurement was carried out using Gilian GilAir5 aspirators equipped with SKC Higgins-Dewell samplers and quartz filters. 3 of the aspirators were located above the barbecue hearth, 3 other in the control area and the other 3 were used as personal samplers to assess the individual exposure of people participating in the grilling process. In all of these three locations one of the sampler were equipped with an adsorbent for the extraction of polycyclic aromatic hydrocarbons (PAHs) in the gas phase, one in a previously weighed quartz filter that was designed to separate from exhaust gases the respirable particulates $\left(\mathrm{PM}_{4}\right)$ containing PAHs and the last one equipped with an adsorbent for the extraction of benzene, toluene and xylene (BTX). We focused on the respirable fraction due to its significant influence of health.

The results of PAHs in the $\mathrm{PM}_{4}$ assessment will be presented. In the normal course of grilling $\mathrm{PM}_{4}$ has been collected. Than 16 polycyclic aromatic hydrocarbon (PAH) congeners were extracted from PM samples and measured quantitatively using GC chromatograph. Result has been calculated for each of the three measurement cycles: the first one using empty grills, i.e. without food, the second with vegetables and the third one with meat dishes (identical set of food was placed on each type of grill). Data concerning PAHs contents in PM was further used to calculate its size dependent deposition in different compartments of human respiratory tract using multiple path particle dosimetry (MPPD) model. Finally a probabilistic risk model was developed to assess the incremental lifetime cancer risk (ILCR) faced by people exposed by breathing to carcinogenic PAHs.

\section{Results}

Using the electric grill and combustion of gaseous fuel (not containing polycyclic aromatic hydrocarbons) in the temperature at the level of about $200^{\circ} \mathrm{C}$ was rather less favorable for PAHs formation in comparison to the traditional grill powered by charcoal and especially charcoal briquettes. The effects of fuel/grill type on the formation of 16 different PAHs indicate a significant increase in PAHs concentrations in case of grill powered by charcoal briquettes. The total concentration of PAHs (over the barbecues hearths) ranged from 1652.1-1704.9 $\mu \mathrm{g} / \mathrm{m}^{3}$ in case of electric grill and 1087.2-5558.5 $\mu \mathrm{g} / \mathrm{m}^{3}$ in case of gas grill to $1538.8-19952.2 \mu \mathrm{g} / \mathrm{m}^{3}$ in case of grill powered by lump charcoal and 13837.6-79561.9 $\mu \mathrm{g} / \mathrm{m}^{3}$ in case of grill powered by charcoal briquettes.

The daily exposure doses of $\mathrm{PM}_{4}$ bound-BaP ${ }_{\text {eq }}$ for typical grill master while preparing food varies from 92-118 ng/day for E and 121-142 ng/day for LP to 124-204 ng/day for LC and 1022$1121 \mathrm{ng} / \mathrm{d}$ for CB. The effect of exposure to PAHs emitted from charcoal briquettes is therefore even 9-12 times higher than in case of electric grill and 7-9 times higher than in case of gas grill. The inhalation-ILCR followed a lognormal distribution with a geometric mean of $2.99 \times 10^{-2}$ $2.71 \times 10^{-1}$ in case of exposure to $\mathrm{PM}_{4}$-bound PAHs emitted by unloaded grills, $6.40 \times 10^{-2}-5.54 \times 10^{-1}$ while grilling vegetables and $4.98 \times 10^{-2}-6.08 \times 10^{-1}$ when grilling meat. The highest values concern the grill powered by charcoal briquettes. The risk in personal exposure of people participating in the grilling process but not being a grill master varies in the range of $1.55 \times 10^{-2}-2.52 \times 10^{-2}$ and in the control area in the range of $5.33 \times 10^{-3}-8.61 \times 10^{-3}$.

The risk for people who inhaled barbeque emission gases for 1,5 hours a day and 20 days a year in the period of 20 years exceeded $10^{-3}$ (which is the US Environmental Protection Agency non-acceptable level), suggesting high probability of cancer occurrences due to PAHs exposure.

\section{Conclusion}


The investigation shows that generally grilling process and especially using charcoal briquettes is dangerous concerning inhalation exposure to PAHs from barbecue exhausting gases. It was also observed that the exposure during preparing meat dishes is higher than in case of grilling vegetables. To protect against such risks it is recommended to use grill relatively rare and with the minimization of time spending over the barbecue hearth as a grill master. This kind of exposure could be highly dangerous for people occupationally exposed to barbecue exhausts.

\section{References}

[1] Badyda A, Grellier J, Dąbrowiecki P. Ambient PM 2.5 Exposure and Mortality Due to Lung Cancer and Cardiopulmonary Diseases in Polish Cities (2016). Advances in Experimental Medicine and Biology, 944:1-9, doi. 10.1007/5584_2016_55

[2] Badyda A., Widziewicz K., Rogula-Kozłowska W., Majewski G, Jureczko I. Inhalation exposure to PM-bound policyclic aromatic hydrocarbons released from barbecue powered by gas, lump charcoal and charcoal briquettes (2017). Advances in Experimental Medicine and Biology, 1023: 11-27, doi. 10.1007/5584_2017_51

[3] Chen SC, Liao CM, Health risk assessment on human exposed to environmental polycyclic aromatic hydrocarbons pollution sources (2006). Sci Total Environ 366(1):112-123

[4] Farhadian A, Jinap S, Abas F, Sakar ZI. Determination of polycyclic aromatic hydrocarbons in grilled meat (2010). Food Control, 21(5):606-610

[5] Kozielska B, Rogula-Kozłowska W, Polycyclic aromatic hydrocarbons in particulate matter in the cities of Upper, Silesia (2014), Waste Management and Environmental Protection, 16(2):75-84

[6] U.S. Environmental Protection Agency. Exposure Factors Handbook: 2011 Edition. Report EPA/600/R-090/052F, Washington, DC

[7] Widziewicz K. and Loska K. (2015) Metal induced inhalation exposure in urban population: A probabilistic approach, doi: 10.1016/j.atmosenv.2015.12.061 